\title{
MIDAS
}

Museus e estudos interdisciplinares

\section{A cultura e a promoção da democracia: recomendações da Carta do Porto Santo para os museus}

Culture and the promotion of democracy: Porto Santo Charter's

recommendations for museums

\section{Sara Barriga Brighenti}

\section{OpenEdition \\ Journals}

\section{Edição electrónica}

URL: https://journals.openedition.org/midas/2749

DOI: $10.4000 /$ midas. 2749

ISSN: 2182-9543

\section{Editora:}

Alice Semedo, Paulo Simões Rodrigues, Pedro Casaleiro, Raquel Henriques da Silva, Ana Carvalho

\section{Refêrencia eletrónica}

Sara Barriga Brighenti, «A cultura e a promoção da democracia: recomendações da Carta do Porto Santo para os museus», MIDAS [Online], 13 | 2021, posto online no dia 15 dezembro 2021, consultado no dia 04 março 2022. URL: http://journals.openedition.org/midas/2749 ; DOI: https://doi.org/

10.4000 /midas. 2749

Este documento foi criado de forma automática no dia 4 março 2022.

\section{(c) (i) (9)}

Midas is licensed under a Creative Commons Attribution-NonCommercial-ShareAlike 3.0 International License 


\section{A cultura e a promoção da democracia: recomendações da Carta do Porto Santo para os museus}

Culture and the promotion of democracy: Porto Santo Charter's recommendations for museums

Sara Barriga Brighenti

\section{A Carta do Porto Santo}

1 A Carta do Porto Santo é um documento promovido pelo Plano Nacional das Artes ${ }^{1}$, desenvolvido no âmbito da Presidência Portuguesa do Conselho da União Europeia $(2021,2)$, realizada em contexto pandémico, que deliberou no seu programa três objetivos: "promover a recuperação, a coesão e os valores europeus" (Europa Resiliente); "valorizar e reforçar o modelo social europeu" (Europa Social); "promover uma Europa aberta ao mundo" (Europa Global).

2 A Carta foi apresentada no dia 28 de abril de 2021, durante a Conferência do Porto Santo: From Democratization to Cultural Democracy: Rethinking Institutions and Practices ${ }^{2}$, numa região ultraperiférica europeia, assumida como centro de irradiação de propostas de política cultural e educativa. A Carta tem o nome desta ilha do arquipélago da Madeira e pretende ser um farol para orientar as políticas, os discursos e as práticas culturais e educativas.

3 A Carta dirige-se aos sectores cultural e educativo e está alinhada com a visão programática apresentada por esta Presidência, na convicção de que estes sectores não podem ficar afastados dos objetivos estratégicos da política europeia. Propõe um mapa orientador de princípios e de recomendações para aplicar e desenvolver um paradigma de democracia cultural na Europa, dirigindo-se a decisores políticos europeus, de todos os níveis (autoridades europeias, governos nacionais, regionais e locais), às 
organizações e instituições culturais e educativas e aos cidadãos europeus, para que se responsabilizem pelo horizonte cultural comum.

4 A cultura tem um poder transformador e a sua ação tem impacto na vida privada dos indivíduos e na organização política das sociedades, por esse motivo a Carta apela a todos nós, enquanto decisores, para que assumamos a responsabilidade pela sua paisagem cultural partilhada. Trata-se de um documento que está ao alcance de todos e pretende ser esse farol que guia a tomada de decisão, quer na vida privada, quer no âmbito profissional, porque as opções de cada cidadão, no exercício da sua cidadania cultural, contribuem decisivamente para uma Europa mais plural, inclusiva e segura. O teor do documento foi elaborado e discutido durante a pandemia covid-19, circunstância que tornou notória a importância da cultura para a qualidade de vida, mas que também contribuiu para erguer novas barreiras no acesso. 0 propósito da Carta é deitar abaixo esses muros e remover os obstáculos à participação cultural, tornando-a o mais ampla possível e reforçando a relevância dos direitos culturais dos cidadãos e o papel da cultura para a qualidade da democracia na Europa.

6 Importa sublinhar a conformidade da Carta com o Plano de Ação para a Democracia Europeia (Comissão Europeia 2020), sendo também devedora de muitos autores e de documentos estratégicos anteriores sobre direitos culturais e o impacto social da cultura (Council of Europe 2005; Conselho Europeu 2006; UNESCO 2010; Council of Europe 2016; European Comission 2018; Roma Capitale e UCLG 2020), a começar pelo artigo 27ํㅡㄹ da Declaração dos Direitos Humanos (Nações Unidas, [1948] 2021): «toda a pessoa tem o direito de tomar parte livremente na vida cultural da comunidade».

7 A Carta do Porto Santo foi elaborada num processo de colaboração, apresentando-se como o resultado de uma metodologia participativa, que evoluiu através da consulta e discussão de premissas e orientações com representantes de 17 Estados-Membros da UE e da Noruega, mais de 16 instituições europeias, associações em rede (tanto no sector cultural como no sector educativo) e por muitos autores de documentos anteriores que foram alimento para as nossas reflexões.

8 O desafio metodológico de desenho da Carta teve por base o modelo participativo e democrático que se desenvolveu em três fases de discussão e debate. Numa primeira fase, o Plano Nacional das Artes criou um projeto de documento com orientações para discussão, seguindo-se a realização de sete grupos de discussão, em formato online, com redes e organizações europeias ligadas à cultura, às artes, ao património e à educação. ${ }^{3}$ Numa segunda fase, o Plano Nacional das Artes criou uma nova versão das diretrizes com as contribuições da primeira fase, sendo o documento depois partilhado com todos os criadores. Seguiram-se reuniões informais com representantes dos países membros da UE, ligados aos Ministérios da Cultura e Educação, bem como com task forces e outros organismos. A versão preliminar da Carta do Porto Santo foi discutida, os representantes partilharam as suas experiências e projetos. Entretanto, algumas das redes europeias promoveram reuniões internas ou sectoriais, adicionando-se as suas contribuições. Numa terceira fase, o Plano Nacional para as Artes criou a versão final da Carta do Porto Santo, com a análise crítica e a contribuição de todos os participantes no fluxo de trabalho. O documento apresenta orientações e recomendações políticas para promover e reforçar a importância das artes e do património para a resiliência da democracia e foi apresentado publicamente na Conferência do Porto Santo. É um manifesto programático que dá voz a muitos agentes que exercem e defendem a cidadania cultural, através do seu papel ativo no seio das instituições em que trabalham 
- nos sectores da cultura, das artes, do património e da educação - e que promovem a democracia.

Em suma, a Carta do Porto Santo é sobre o reconhecimento do valor e da urgência da cidadania cultural para a saúde da democracia, hoje e no futuro.

\section{As palavras importam!}

10 As palavras têm uma história, incorporam ideologias, por isso é fundamental validar o discurso que usamos. Os conceitos não exprimem apenas o que existe, não são rótulos que substituem as coisas. As palavras e os conceitos projetam e moldam realidades, abrem ou fecham horizontes, dão ou retiram valor e trazem consigo preconceitos e estruturas de análise do mundo. Cultura ou culturas? Democratização ou democracia? Público ou audiências? Consumidores ou protagonistas?

11 Novos contextos exigem novas perguntas e respostas. O mundo pede paradigmas e ações renovados, especialmente quando as situações que se vivem não encontram replicação adequada no paradigma dominante. Neste caso é preciso reformulá-lo, sabendo que é urgente um modelo político que se adeque às circunstâncias, das comunidades e dos territórios, do presente e do futuro, ao nível ambiental, económico, social, que se centre nas necessidades das pessoas e da natureza, na justiça e no bemestar planetário.

O modelo de democracia cultural visa a criação de estruturas descentralizadas e plurais, que corrijam iliteracias e desigualdades no acesso à informação em diferentes áreas do conhecimento - científica, humanista, artística, ambiental. Com este objetivo os intervenientes são chamados a participar na definição desse léxico cultural que falta, a criar um renovado conjunto de práticas culturais que nos permitam abrir caminhos e possibilidades alternativas, ainda não imaginadas: em suma, precisamos de novas palavras e ações, para criar novas realidades.

\section{Democracia cultural, hoje! As instituições culturais e a saúde da democracia}

13 A democracia não é uma condição dada, é um processo, mais do que uma conjuntura estática e permanente. Em democracia o dissenso é fundamental e a diversidade um trunfo. Nela valorizam-se os interesses e as necessidades dos cidadãos; dá-se-lhes voz e possibilidade de escolha. Justamente, a democracia é fortalecida quando os cidadãos afirmam os seus direitos e deveres, em qualquer ato, como iguais. Mas hoje o que parecia estabilizado e certo, revela-se inseguro e reversível. 0 tema da fragilidade da democracia manifesta-se assim, uma vez mais, central nas nossas sociedades. Parecenos por isso fundamental repensar a participação ativa dos cidadãos na construção da sociedade que serve, as pessoas e o planeta, porque o estilo próprio da democracia é o confiar na inteligência cooperativa e no pluralismo: no reconhecimento da multiplicidade de vozes e na valorização e integração das diferenças.

14 Neste sistema político, todos os cidadãos elegíveis têm o poder de escolha, mas não basta apontar ou desejar uma sociedade democrática, temos que atuar desse modo, até porque podemos viver num estado democrático e, no entanto, diferentes dimensões da vida comunitária permanecerem autoritárias e antidemocráticas. Por esta razão é 
preciso questionar a natureza das relações de poder que se estabelecem nas instituições e nas práticas culturais e educativas: como partilhar a autoridade? Como pode a vivência cultural e a educação ajudar a emancipar em vez de embrutecer? É sobre tudo isso a democracia cultural - um paradigma que enquadra a relação entre instituições, o sector cultural e o público, postulando o desejo de uma participação mais ativa e comprometida assimilando as práticas culturais de grupos sociais diferentes, preservando práticas culturais próprias e recriando modos de estar e de interpretar o mundo, de forma inovadora e integradora, que promovam o sentido de pertença e o bem-estar social. Neste enquadramento, a cultura não é uma mercadoria, mas um espaço aberto para que cada cidadão se possa envolver, ter uma posição, escolher e assumir a responsabilidade de moldar a sua própria cultura - e a cultura de todos. A democracia é uma metodologia social dinâmica que pressupõe a partilha do poder.

A pandemia covid-19 expôs a marginalidade do sector cultural e o levantamento de ainda mais barreiras à participação cultural e à criação, por isso perguntamos: no contexto atual, devemos seguir usando os modelos anteriores, ou é nosso dever criar novas propostas, novos paradigmas? Ainda marcados pela pandemia, parece-nos válido refletir sobre como podem os valores democráticos ser garantidos pelos museus, enquanto instituições culturais com missão educativa e social. Estes valores refletem-se na missão, no plano, programa, no orçamento, nos recursos ou na comunicação das instituições? As suas políticas de acesso garantem a inclusão e a equidade?

Com efeito, não basta desejar uma sociedade mais democrática - devemos agir para a defender. Por isso consideramos essencial reafirmar a função política dos museus, enquanto lugares públicos de conhecimento e de questionamento crítico, as suas missões, os seus processos e modos de organização institucional, o que valorizam e propõem. Os museus são organizações que influenciam positivamente a saúde da democracia junto das comunidades que servem.

Porém, muitos museus são estruturas orgânicas frágeis. Terão estas instituições os meios para atingir estes objetivos? Como podem ajudar a emancipar os públicos se estão desprovidos dos recursos necessários? De facto, para responder não é suficiente postular princípios, é urgente diagnosticar o que falta aos museus para que possam cumprir as suas missões, dotá-los dos meios para estudar e monitorizar os seus públicos, captar públicos potenciais, capacitar equipas e diversificar os seus perfis e funções, para que possam assim responder às exigências de uma sociedade plural, com tendências e mundividências cada vez mais conflituantes. ${ }^{4}$

\section{Construir um território comum}

Como podem os museus pôr em prática o paradigma da democracia cultural ${ }^{5}$ ? Será possível equilibrar a ambição de qualidade e de excelência na criação de obras artísticas, na programação e exposição, no estudo, na defesa e na divulgação do património com os objetivos da participação, diversidade e inclusão em mente?

A qualidade e a excelência são construções culturais baseadas em critérios subjetivos, associados a grupos, estilos, épocas e gostos. Estarão os museus disponíveis para debater com aqueles que não partilham os mesmos critérios? E ainda, assumir que a excelência ou a qualidade não estão apenas vinculadas ao produto, mas podem ser encontradas no processo, na mediação entre a obra e os públicos. A este respeito, $a$ Carta do Porto Santo defende que é fundamental compreender que hierarquizar valores 
culturais implica, sempre, formas de poder e de autoridade - de que é preciso estar muito consciente. Assim, manter o objetivo da excelência é possível, sempre que aqueles que definem a excelência sejam abertos e inclusivos nos pressupostos e critérios de qualidade e não os transformem em formas de exclusão. O sistema de qualidade não pode ser mais uma forma de reforço da desigualdade, de distinção social e de reprodução do gosto elitista.

20 A democratização da cultura, o paradigma anterior dominante, propõe tornar acessíveis, ao maior número de pessoas, as obras-primas da humanidade e, em primeiro lugar, as do país em causa. Trata-se, portanto, de uma visão que hierarquiza a cultura em erudita, de massas e popular, sendo a erudita aquela que merece ser difundida para o "todos", porque é a que tem "qualidade". Esta visão bem-intencionada, embora paternalista e descendente da cultura (no singular), assumiu uma noção genérica de "público" ou "audiência". Vários estudos revelam (Lopes 2009; Wilson, Gross e Bull 2017; Bonet e Négrier 2018) como a sua implementação, desde os anos de 1950-1960, não atingiu os efeitos desejados: o tão ambicionado aumento dos públicos da cultura não aconteceu. $\mathrm{O}$ acesso social e simbólico aos bens culturais cristalizou-se. E praticamente não foi promovida a pretensa diversidade (étnica, racial, etária, socioeconómica). Pelo contrário, prevaleceu uma abordagem hierárquica da cultura, baseada em pressupostos de qualidade e de excelência - determinados pela minoria, isto é, os curadores, os conservadores, os diretores - e no modelo da visão única, para todos, colocando o visitante num nível subalterno e passivo, desvalorizando o que os visitantes conhecem e podem trazer para o museu. Desta forma, postulou-se a noção de que o visitante é tão só um consumidor de cultura e, nesse sentido, não se respeitaram os seus direitos culturais, enquanto criador e produtor de cultura.

21 É um facto que nos museus os modelos de autoridade prevalecem sob diferentes formas, refletem-se na definição dos valores dos ingressos, nas formas de informar e de acolher, na clareza da linguagem, no léxico, nos programas de interpretação, na museografia, no acesso às exposições temporárias e a outras áreas, no acesso às coleções ou às atividades dos museus, na arquitetura, no design... Para combater estas formas de autoridade, mais ou menos visíveis, é preciso que delas se tenha consciência, porque, em todos os casos, a sua implementação precede uma tomada de decisão cuja intenção, mais ou menos lúcida, mais ou menos assumida, é incluir ou excluir. 0 modo como a instituição desenvolve a sua política social reflete-se assim no modo como exerce o seu poder.

Os museus, e especialmente os museus de arte, têm sido dominantemente considerados pela sociedade como instituições públicas de caráter elitista. Apesar disso, hoje em dia, ao olharmos para os museus percebemos que está em curso uma enorme transformação de visão, sobretudo quando passaram a focar as suas missões nas questões sociais e educativas, reconhecendo que o seu foco não poderia centrar-se apenas nas coleções. Contudo, verificou-se também que apostar nas medidas de promoção do acesso, especificamente no que diz respeito às questões financeiras, às acessibilidades físicas ou intelectuais, não é tão pouco suficiente! Há que constatar que as barreiras simbólicas que os museus incorporam são ainda a razão fundamental para que certos públicos não os visitem, mesmo quanto têm interesse e motivação. É urgente identificar e remover estas barreiras relacionadas com representatividade: os valores que defendem, as narrativas da exposição, a linguagem, as instalações... Porque, como sabemos, se as pessoas não se sentirem representadas pelos museus, não sentem que lhes pertencem - 
assim, dificilmente desejam participar, particularmente porque não confiam que são realmente incluídas ou reconhecidas na sua diversidade, sentindo-se "outro".

Por certo, o modelo de governança espelha a cultura da instituição: nos processos de tomada de decisão, nos modos de organização, na comunicação, na mediação, na programação, no acolhimento ou nas relações entre os diversos atores envolvidos - i.e. nas formas de ser e de fazer-se museu.

Com honestidade e coerência, os museus podem comprometer-se com a emancipação dos públicos, reconhecendo-os como parte integrante do complexo sistema museal (e não como meros utilizadores passivos, que assistem às exposições e participam nas atividades que lhes são propostas) e comprometendo-se com o seu bem-estar, e, de forma mais lata, com o bem-comum.

\section{Juntos}

25 A democracia cultural, como forma de governo das organizações, exige que a participação e a representação da diversidade sejam matriciais na tomada de decisão. Neste modelo, é fundamental investir nas equipas, nas relações entre pares, no desenvolvimento da confiança para promover a integração de todos, quer sejam externos ou internos. Para o fazer existem códigos e práticas culturais que precisam ser dominados para que as relações e a comunicação sejam eficazes. Há preconceitos a ultrapassar. Além disso, para promover a participação dos que estão "fora" da instituição é necessário olhar para o museu e para quem o representa, procurando identificar também nas equipas as comunidades que se pretendem servir ${ }^{6}$, as competências que os planos estratégicos requerem, e assim, criar novas funções para novas missões, abrindo as instituições, não ao Outro (aquele que não pertence), mas a um propósito comum.

Tudo isto implica ir além de si próprio, trabalhar junto, desierarquizar, promover lideranças colaborativas e servidoras, reduzir relações descendentes e desiguais. Desta forma é possível construir um "terreno comum".

Mike Murawski (2016) lembra que os museus são feitos de pessoas e para pessoas «museums are us not it»-, e que os museus são espaços transformadores de ligação humana:

When we talk about them only as brick-and-mortar institutions or as 'it', it becomes easier to distance ourselves from the human-centered work we do. So it's absolutely essential to remember that museums are made of people (...): from directors, board members, patrons, and curators to educators, guest services staff, registrars, conservators, security guards, volunteers, maintenance and facilities workers, members, visitors, etc.

[...] So if we, myself included, say 'museums must be more connected to their communities', we're really talking about what the people that make up the museum need to focus on - being more connected to our communities. We are inseparable from the institution, in other words. Any critique of museums is a critique of us; and any change needing to happen in museums is, therefore, a change that needs to start with us. (Murawski 2016, n.p.) 


\section{Um lugar à mesa: valores comuns e confiança}

28 A fidelização dos públicos é alcançada sobre o valor da confiança. Para desenvolver a confiança é necessário tempo, ação concreta, partilha, diálogo. Com efeito, a confiança atinge-se quando todos trazem valor à mesa e executam em conformidade, o que implica compromissos reais e sobretudo a disponibilidade para se colocar numa posição subalterna, de escuta e de aprendizagem, com o outro e para o outro. Consequentemente, para consolidar uma política de democracia cultural, os museus precisam de conhecer melhor os seus visitantes (reais e potenciais), a fim de os convidar para as experiências que vão ao encontro das suas necessidades, interesses e expectativas. Quando falamos de confiança, falamos também de empatia porque se trata de uma relação humana, pelo que "conhecerem-se uns aos outros" é muito diferente de imaginar quem são estas pessoas. É preciso intimidade para estar aberto à sua diversidade, evitando a reprodução de modelos hierarquizados, criando familiaridade, novos hábitos e perceções, construindo espaços de inclusão que são também uma mudança de quem acolhe.

Em democracia cultural valoriza-se a mediação e o reconhecimento de códigos e de práticas culturais que aproximam, desmistificam e geram novas relações. Então prevalecem os desafios: como e o que programar? Como e o que mostrar? Como comunicar? Como mediar? Que outros usos ou apropriações podem ser feitas de um espaço? Como conjugar diferentes pontos de vista e aprender com eles?

Por tudo isto, os museus devem investir em estudos de público regulares, com o propósito de adaptar estratégias a favor de necessidades e de interesses concretos, isto especialmente se pretenderem que os visitantes se tornem protagonistas empenhados em vez de consumidores passivos.

31 Além do mais, a formação de públicos deve ter uma estratégia e um projeto com critérios definidos que não se baseiem apenas na confirmação das expectativas desses públicos, sem os transformar. Essa formação deve ser feita valorizando o que sabem e propõem. Explicitando, negociando, ouvindo, suscitando novas interrogações. Neste âmbito, as políticas museológicas devem valorizar a participação dos públicos, apelar e atender à sua manifestação, expressão e à sua criatividade.

\section{Os museus não são neutros}

32 Ao incluir questões sociais mais amplas e emergentes em programas e exposições públicas, os museus estão a destacar conteúdos que realmente interessam e impactam a sociedade contemporânea. Estão também a promover a pluralidade de vozes, e desta forma podem diversificar os modos de olhar as coleções e de narrar as suas his(es)tórias através de pontos de vista mais abrangentes, inclusivos e críticos.

33 Mais uma vez, esta possibilidade de levantar questões, especialmente questões difíceis até narrativas conflituantes, deve ser assumida na missão da instituição. Para tanto, os seus órgãos de supervisão devem valorizar a assunção de riscos e apoiar as equipas, fornecer recursos, tempo, liderança - estas são algumas das pedras angulares da integridade institucional.

34 Além disso, os temas que são convocados para as exposições, mais do que emergir das próprias coleções devem emergir dos contextos, das comunidades e dos territórios, 
para que possam realmente afetar e sensibilizar as pessoas, ter reflexos no seu entorno, nos comportamentos e nos posicionamentos sociais. Escolher não consultar as comunidades a este respeito ou mesmo investir em programas desconexos relativamente ao tempo presente é perder a oportunidade de ser relevante, em termos educativos, sociais e culturais.

Os museus que se envolvem com as comunidades e implementam a democracia cultural exercem práticas que substituem a autoridade pela autoregulação. Não se trata de ir ter com as pessoas e pedir-lhes que colaborem fazendo algo que está previamente definido. Trata-se de criar oportunidades para envolver o grupo na conceção criativa do projeto, implicando-o plenamente em cada passo do processo. Como se afirma no Plano de Ação para a Democracia Europeia: "cidadãos empenhados, informados e capacitados são a melhor garantia de resiliência para as nossas democracias» (Comissão Europeia 2020, 3). Encorajar o surgimento dos projetos a partir dos contextos e das comunidades é uma forma de garantir a relevância.?

\section{Cultura é currículo}

36 A cultura contribui para dar sentido à realidade, moldando os aspetos menos tangíveis da vida. Ao inspirar indivíduos e comunidades, os museus tornam-se lugares-chave para a aprendizagem, justamente porque ajudam a construir sentido através de his(es)tórias e de objetos que testemunham acontecimentos marcantes, os quais relacionam o que cada um sabe e traz consigo, com factos reais, com pessoas reais, aprendendo nessa relação.

37 A Carta do Porto Santo baseia-se na crença de que para consolidar as políticas de democracia cultural, as ligações estruturais e estratégicas entre cultura e educação são prioritárias. A Carta defende a transformação das instituições culturais em territórios educativos, e das instituições educativas em polos culturais. Desde o pré-escolar à universidade, e ao longo da vida.

38 Ao trabalhar em parceria com a educação formal, os museus sublinham que cultura é currículo, encorajam a participação dos estudantes e, para além disso, podem incentivar o seu envolvimento na tomada de decisão sobre questões relacionadas com o imperativo de salvaguarda do património cultural, com modos de expor ou formas de comunicar. A Carta refere que os museus devem convidar os jovens a participar nos seus conselhos consultivos, a coorganizar, cocomissariar exposições e programas públicos, a interpretar coleções. Ao fazê-lo estarão a sensibilizar os jovens para a cidadania cultural e para a tomada de consciência sobre o poder da mudança que se exerce quando são cumpridos os seus direitos e deveres culturais.

Para que a democracia prospere, os estudantes precisam cada vez mais de usufruir de uma educação crítica e democrática. Quando afirma que a educação é o laboratório da democracia, a Carta propõe uma pedagogia da democracia que encoraje o maior envolvimento dos jovens na construção da sociedade, onde as cidadanias políticas e culturais se fundem para a projeção de futuros sustentáveis. 


\section{Mind the gap}

40 Ansiedade, depressão, isolamento, solidão são problemas concretos do nosso tempo. Todos eles têm uma elevada prevalência nos jovens, porque muitos jovens perderam a esperança no futuro. Perguntamos novamente: $O$ que podem os museus fazer a este respeito? Esta Carta recomenda que as instituições culturais, como os museus, convidem os jovens para participar e para decidir. Entendendo-se que a convivência e a colaboração ajudarão a articular linguagens e a valorizar competências, opiniões, crenças, prioridades... A troca será profícua para ambas as partes e pode realmente dar esperança e construir caminho no sentido de preparar as próximas décadas. Os museus que o fizerem de forma humilde, aberta e verdadeiramente interessada, vão liderar, porque desta forma aprenderão com os jovens os "caminhos" que os ligam ao futuro e, assim poderão contribuir para emancipar uma geração, articulando-a com as anteriores.

41 Jacques Rancière diz na sua obra intitulada $O$ Mestre Ignorante - Cinco Lições sobre a Emancipação Intelectual «(...) quem emancipa não tem que se preocupar com aquilo que o emancipado deve aprender. Ele aprenderá o que quiser, nada, talvez» (Rancière 2007, 37). 0 seu pensamento defende que o princípio da desigualdade embrutece e o princípio da igualdade emancipa; advoga que numa relação de reciprocidade o reconhecimento da igualdade de competências de ambas as partes é basilar e é o ponto de partida trata-se de um posicionamento que parte de uma igualdade a ser verificada, não de uma desigualdade a ser reduzida; Trata-se de uma razão de igualdade a ser assumida filosófica e politicamente na relação com o outro, que muito pode alterar a forma como as instituições culturais veem e lidam com os seus públicos mais jovens.

\section{O meio digital}

42 Se a cidadania cultural é o exercício dos direitos e dos deveres culturais, os territórios digitais devem ser compreendidos como mais um meio com possibilidades próprias para ampliar essa divulgação, participação e produção cultural. As interfaces digitais têm um impacto profundo na forma como nos relacionamos com a informação, o conhecimento e a interação social. É crucial reconhecer o potencial democrático que as plataformas digitais e as redes sociais congregam, alargando o acesso à informação e mesmo à produção, até do ponto de vista da criação: há património a ser criado neste território!

43 O digital é, também, uma ferramenta que facilita processos de interação e de partilha dentro das instituições e entre estas e os cidadãos, compreendidos como colaboradores. As ferramentas digitais são úteis para escutar as pessoas e as comunidades, propondo novas metodologias de cooperação, multiplicando e partilhando práticas e ideias, quer nos circuitos internos das organizações, quer nas relações que estas estabelecem com o exterior, e até para as envolver na definição das políticas culturais.

A digitalização é ainda fundamental para superar os obstáculos físicos, os binómios: urbano-rural ou centro-periferia. Além disso, a digitalização pode fomentar novas formas de criação e de apropriação de informação, para além de promover desafios globais, como a igualdade, a sustentabilidade, $o$ acesso. 

território digital, como a atual pandemia veio demonstrar, é também espaço de exclusão. Não podemos deixar de pensar em soluções para mitigar as barreiras que este território impõe. Capacitar para a cidadania cultural implica também desenvolver, a montante, políticas de acesso, inclusão e literacia digital. Os fenómenos de desinformação, roubo e exposição de dados privados, de ataque a expressões culturais específicas ou minoritárias, bem como de privatização do espaço digital, devem ser acautelados e combatidos.

\section{Longo prazo}

Para implementar políticas de democracia cultural as instituições devem investir em projetos a longo prazo e na gestão da mudança. Devem investir no seu contrato social, mas para isso têm de definir ciclos mais longos de planeamento, financiamento, monitorização e avaliação.

A transformação ocorre durante o processo, ou seja, quando são adquiridas novas competências, alterados comportamentos e desenvolvidas capacidades. A Carta do Porto Santo recomenda às instituições que usem instrumentos para avaliar o impacto social das suas políticas, projetos e programas culturais, centrando a análise nos processos, nos contextos, na duração e na sustentabilidade, procurando nestes critérios a bússola para orientar e para monitorizar a transformação que ocorre no longo prazo.

48 A este respeito, o modelo de democracia cultural pede aos museus que repensem os critérios e parâmetros de avaliação (internos e externos): equilibrem os indicadores quantitativos e econométricos, com indicadores de qualidade, que forneçam dados relativos ao impacto da cultura na vida dos cidadãos, tais como aprendizagem, sociabilidade, coesão, capacitação, compromisso, bem-estar, confiança ou mesmo esperança.

Os resultados dos projetos devem apresentar caminhos para além de números, é preciso contar his(es)tórias que contextualizem os resultados e inspirem a imaginação, abram novas possibilidades na tomada de decisão, provocando, de forma criativa e adequada, as mudanças necessárias ao sector.

\section{Ins-tituições vs ex-tituições: criar novos conceitos}

As instituições democráticas também trabalham com o que provém das margens e por isso têm muitos centros. Ao visualizar "ex-tituições" em vez de instituições, estamos a compará-las com faróis que iluminam os territórios mais distantes, porventura alheados, valorizando, através deles, novas formas de relação, de solidariedade e de cooperação. As "ex-tituições" ousam mudar as suas práticas, apesar dos preconceitos, dos medos e até dos obstáculos, para poder responder à necessidade de criar espaços seguros para ideias "inovadoras". Neste sentido, o seu papel é essencial à criação humana e consequentemente à imaginação e projeção de futuros.

51 Com fortes lideranças colaborativas os museus podem trabalhar em rede com todo o território e as comunidades. Os museus enquanto ex-tituições dinamizam uma relação sistémica, na e com a sociedade, não se posicionando apenas como organizações que servem para preservar e comunicar o passado, mas para o colocar em relação ao 
presente, considerando para tal a diversidade dos contextos que servem e a multiplicidade de agentes que operam nestas redes. Museus como interfaces ou como pólos transsectoriais de criação, cooperação, produção e fruição cultural.

\section{Conclusão}

52 A democracia cultural é um paradigma que enquadra as relações entre as instituições e agentes dos sectores cultural e educativo e os públicos, postulando o desejo de uma participação mais ativa e um reconhecimento das práticas culturais dos diferentes grupos sociais. Pede às instituições mudança nos quadros políticos, de financiamento e de gestão, e novos modelos de governação centrados nas pessoas: para, com e pelas pessoas, assumindo que todos são agentes culturais igualmente relevantes para o sistema.

Em particular, os museus, enquanto organizações centradas no ser humano, podem tornar claros os seus valores: humanidade, liberdade, inclusão, equidade, diversidade, confiança, serviço, cooperação, estabilidade, segurança, sustentabilidade, incluindo-os nas suas missões e agendas. Nesse sentido, há 22 anos, Stephen Weil (1999) argumentou que existe uma espécie de pacto entre os museus e a comunidade. Weil acreditava que os museus poderiam prosperar desde que estivessem numa relação de reciprocidade com as pessoas. Que os museus tinham que ser para alguém, não se limitando a ser sobre algo. A Carta do Porto Santo propõe a centralidade das pessoas e dos processos que promovem os valores democráticos, para que cada cidadão e cada comunidade possam escolher participar e responsabilizar-se pelo horizonte cultural de todos.

\section{BIBLIOGRAFIA}

"Carta do Porto Santo. A Cultura e a Promoção da Democracia: Para uma Cidadania Cultural Europeia." 2021. https://portosantocharter.eu/wp-content/uploads/2021/05/

CartaDoPortoSanto.pdf

Bonet, Lluis e Emmanuel Négrier. 2018. "The Participative Turn in Cultural Policy: Paradigms, Models, Contexts." Poetics 66: 64-73.

Camacho, Clara Frayão, coord. 2021. Grupo de Projeto Museus no Futuro: Relatório Final. Lisboa: Direção-Geral do Património Cultural. http://patrimoniocultural.gov.pt/static/data/docs/ 2021/02/15/RelatorioMuseusnoFuturo.pdf

Comissão Europeia. 2020. “Comunicação da Comissão ao Parlamento Europeu, ao Conselho, ao Comité Económico e Social Europeu e ao Comité das Regiões sobre o Plano de Ação para a Democracia Europeia (COM(2020) 790 final)." https://eur-lex.europa.eu/legal-content/PT/TXT/ PDF/?uri=CELEX:52020DC0790\&from=EN

Conselho Europeu. 2006. "Recomendação do Parlamento Europeu e do Conselho de 18 de Dezembro de 2006 sobre as Competências Essenciais para a Aprendizagem ao Longo da Vida 
(2006/962/CE)." Jornal Oficial da União Europeia 394: 10-18. https://eur-lex.europa.eu/legalcontent/PT/TXT/PDF/?uri=CELEX:32006H0962\&from=EN

Council of Europe. 2005. "Council of Europe Framework Convention on the Value of Cultural Heritage for Society." Council of Europe Treaty Series, 199. https://rm.coe.int/1680083746

Council of Europe. 2016. The Indicator Framework on Culture and Democracy: Investigating the Link Between Culture and a Democratic, Open and Trusting Society. Strasbourg: Council of Europe.

European Commission. 2018. "Commission Staff Working Document: a New European Agenda for Culture - Background Information [SWD(2018) 167 final]. Accompanying the document: Communication from the European Commission to the European Parliament, the European Council, the Council, the European Economic and Social Committee and the Committee of the Regions. A New European Agenda for Culture [COM(2018)267 final]." https://eur-lex.europa.eu/ legal-content/EN/TXT/PDF/?uri=CELEX:52018SC0167\&from=EN

Lopes, João Miguel Teixeira. 2009. "Da Democratização da Cultura a um Conceito e Prática Alternativos de Democracia Cultural." Cadernos de Estudo 14: 1-13.

Murawski, Mike. 2016. "The Urgency of Empathy \& Social Impact in Museums." Art Museum Teaching: A Forum for Reflecting on Practice, 11 July. https://artmuseumteaching.com/2016/07/11/ the-urgency-of-empathy-social-impact-in-museums/

Nações Unidas. (1945) 2021. “Declaração Universal dos Direitos Humanos.” https://unric.org/pt/ declaracao-universal-dos-direitos-humanos

Rancière, Jacques. 2007. O Mestre Ignorante: Cinco Lições sobre a Emancipação Intelectual. Tradução de Lílian do Valle. 2. ed. edelo Horizonte: Autêntica.

Roma Capitale, UCLG (United Cities and Local Governments). 2020. "The 2020 Rome Charter: The Right to Participate fully and Freely in Cultural Life is Vital to our Cities and Communities." https://www.2020romecharter.org/MC-API/Risorse/StreamRisorsa.ashx?guid=e8c4f74ac517-480b-91e2-ee37e9b0af34

UNESCO. 2010. Seoul Agenda: Goals for the Development of Arts Education. http://www.unesco.org/ new/fileadmin/MULTIMEDIA/HQ/CLT/CLT/pdf/Seoul_Agenda_EN.pdf

Weil, Stephen E. 1999. "From Being about Something to Being for Somebody: The Ongoing Transformation of the American Museum.” Deadalus 128 (3): 229-258.

Wilson, Nick, Jonathan Gross, e Anna Bull. 2017. Towards Cultural Democracy: Promoting Cultural Capabilities for Everyone. London: King's College London.

\section{NOTAS}

1. O Plano Nacional das Artes (www.pna.gov.pt) é uma estrutura de missão com o horizonte temporal 2019-2029 sob tutela do Ministério da Cultura e do Ministério da Educação e com articulação estratégica com o Ministério da Ciência, Tecnologia e Ensino Superior. Contempla parcerias com a administração local, entidades privadas e a sociedade civil, com o propósito de dar um lugar central às artes e ao património na formação ao longo da vida, corrigindo as desigualdades nesse acesso. A missão do Plano Nacional das Artes é promover a transformação social, mobilizando o poder educativo das artes e do património na vida dos cidadãos: para todos e com cada um. Os principais objetivos são garantir o acesso e a participação dos cidadãos na fruição das artes e da produção cultural; expandir a oferta cultural educativa e promover o 
conhecimento, a integração e o encontro de culturas. A sua estratégia/manifesto foi apresentada publicamente no dia 18 de junho de 2019, para o período de cinco anos (2019-24).

2. A Conferência do Porto Santo (27-28 abril 2021) foi organizada com um formato híbrido (com participantes registados de 24 estados-membros EU, num total de 38 países) e teve o apoio do Governo Regional da Madeira e da Câmara Municipal de Porto Santo. 0 objetivo deste encontro europeu foi refletir sobre a relação entre cultura e democracia e os paradigmas de relação entre as instituições culturais e os seus públicos. Contou com a participação do Vice-presidente da UE, do Diretor para a Cultura da UNESCO, da Presidente do Comité para a Cultura e Educação do Parlamento Europeu, do Diretor para a Democracia do Conselho da Europa, da Ministra da Cultura, do Ministro da Educação, do Secretário Regional do Turismo e Cultura do Governo Regional da Madeira, do Presidente da Câmara Municipal do Porto Santo, e conferencistas de reconhecido mérito internacional, como Jacques Rancière, Chantal Mouffe, Maria Lind, Wayne Modest, Maria Acaso, entre outros, e a apresentação de projetos artísticos com dimensão educativo-social e de emancipação dos cidadãos.

3. Estes grupos de discussão envolveram os representantes dos Estados-Membros e as principais redes culturais, artísticas e patrimoniais europeias e internacionais de referência, como ACEnet; Association Européenne des Conservatoires, Académies de Musique et Musikhochschulen; Culture Action Europe; Culturdata; Cultumetria; ECCOM - European Center for Cultural Organisation and Management; ENO - European Network of Observatories in the Field of Arts and Cultural Education; European Cultural Foundation; European Music Council; European Network of Cultural Centres; Europeana; ICOM Europe; ICOM PT; ICOMOS Europe; ICOMOS PT; INSEA International Society for Education through Art; Interarts; Michael Culture; NEMO - Network of European Museum Organisations; Trans Europe Halles.

4. Consultar, por exemplo, o relatório final do Grupo de Projeto "Museus no Futuro" (Camacho 2021) para conhecer a caracterização da realidade dos 37 museus, palácios e monumentos sob a alçada do Ministério da Cultura, em 2020. Este relatório apresenta também tendências de futuro e fatores de mudança (confiança e bem-estar, mutações demográficas, turismo, tecnologias digitais, participação e sustentabilidade) com impacto no sector dos museus e do património. Inclui ainda 50 recomendações e propostas para serem consideradas no âmbito das políticas públicas no horizonte 2030, no sentido de preparar o sector para os desafios e cenários do futuro.

5. A democracia cultural promove a criação de condições para uma participação mais ativa e para o reconhecimento das práticas culturais de diferentes grupos sociais; baseia-se na mudança de uma relação de consumo para uma relação de compromisso; valoriza o que cada pessoa sabe, as suas tradições, as suas vozes, a cultura local e outras manifestações culturais.

6. Inclusivamente, através da constituição das equipas, o museu pode decidir espelhar a diversidade cultural das comunidades que assiste. Fazê-lo pressupõe diversificar os perfis técnicos, alterar as descrições de funções, repensar as formas de recrutamento. Desta forma, mostrará que assume a inclusão e a representação como valores institucionais.

7. Neste caso importa esclarecer que em democracia cultural emergir do contexto também significa valorizar a tradição artística ou as manifestações patrimoniais da humanidade, ambas podem assumir predominância na visão de um projeto. $O$ alerta que deixamos é para evitar a hipervalorização das identidades culturais locais ou especificas, sem a abertura de novos horizontes. 


\section{RESUMOS}

A Carta do Porto Santo (2021) é um documento programático que tem o nome da ilha onde foi apresentado, uma região ultraperiférica europeia, assumida como centro de irradiação de propostas de política cultural e educativa. Esta Carta Europeia pretende ser um farol para orientar as práticas e os discursos dos governos, instituições e cidadãos, com o propósito de remover os obstáculos à participação cultural, tornando-a o mais ampla possível, desta forma reforçando a relevância dos direitos culturais das pessoas. A Carta do Porto Santo reflete sobre o papel que os sectores da cultura, artes, património e educação desempenham na promoção da democracia. 0 teor do documento aborda questões que promovem o papel da cultura para a saúde da democracia; a diferença entre democratização e democracia cultural; a centralidade dos territórios digitais; a inter-relação entre cultura e educação. Contém 37 recomendações que propõem formas de incentivar as autoridades europeias, as instituições culturais e os cidadãos a implementar a democracia cultural, através da partilha do poder que detêm e da promoção dos direitos culturais dos cidadãos. Este ensaio segue a visão da Carta e propõe uma reflexão sobre as implicações do modelo de democracia cultural para os museus, indicando modos de "ser" e de "fazer" o museu enquanto lugar e instrumento de cidadania cultural, para que com ele cada cidadão e cada comunidade possa escolher participar e assumir a responsabilidade pelo horizonte cultural de todos.

The Porto Santo Charter (2021) is a programmatic document that bears the name of the island where it was first presented, an outermost European region taken as an irradiation centre of cultural and educational policies. This European Charter is intended to be a beacon to guide the practices and discourses of governments, institutions and citizens, with a view to removing obstacles to cultural participation, thus reinforcing the relevance of people's cultural rights. The Porto Santo Charter focuses on the role that culture, arts, heritage and education sectors play in the promotion of democracy. The content of this document addresses issues that promote the role of culture for the health of democracy; the difference between democratization and cultural democracy; the central role of digital territories; the inter-relationship between culture and education. It contains 37 recommendations proposing ways to encourage European authorities, cultural institutions and citizens to thrive for cultural democracy by sharing the power they hold and promoting citizens' cultural rights. This essay follows the Charter's vision and proposes a reflection on the implications of the cultural democracy model for museums, indicating ways museums can enact as places and instruments for cultural citizenship, so that every citizen and community may choose to participate and take responsibility for the cultural horizon of all.

\section{ÍNDICE}

Keywords: cultural policies and museums, cultural democracy, museums and education, cultural participation, Charter of Porto Santo

Palavras-chave: políticas culturais e museus, democracia cultural, museus e educação, participação cultural, Carta de Porto Santo 


\section{AUTOR}

\section{SARA BARRIGA BRIGHENTI}

É especialista em museus, educação e programação artística. Atualmente, é subcomissária do Plano Nacional das Artes e participou na organização e elaboração da Carta do Porto Santo (2021). Foi membro do grupo de projeto que produziu o relatório "Museus no Futuro" (2021). Foi diretora do Museu do Dinheiro (Lisboa) do Banco Central de Portugal, responsável pela instalação do museu, plano de exposições, edições, programas públicos e projetos com as comunidades. Antes, tinha sido coordenadora de educação da Casa das Histórias Paula Rego (Cascais) e assessora para os sectores de educação e envolvimento de públicos em teatros, museus e património cultural. Foi assessora do Ministério da Educação para o currículo do ensino artístico especializado e participou em projetos-piloto da UNESCO e do Alto Comissariado para as Migrações.

Plano Nacional das Artes, Campo Grande, n. 83, 1.ำ 1700-088 Lisboa, Portugal, sarabrighenti@pna.gov.pt 